\title{
O GRUPO BAMBUÍ NA FOLHA LUZ (SE-23-Y-D-V)
}

\author{
Matheus Kuchenbecker' e Antônio Carlos Pedrosa-Soares ${ }^{2}$
}

\section{Resumo}

\begin{abstract}
Sintetiza-se aqui resultados obtidos durante o mapeamento da Folha Luz (SE-23-Y-D-V), realizado por meio de contrato entre o CPMTC/UFMG e a CODEMIG. Na região mapeada predominam rochas pelíticas e carbonáticas Neoproterozoicas do Grupo Bambuí, deformadas sob influência da Faixa Brasília, a oeste. A análise dos dados sedimentológicos e estratigráficos coletados indica para as rochas do Grupo Bambuí uma gênese marinha, em ambientes que variam de marinho plataformal proximal a distal. As rochas apresentam deformação de regime dúctil-rúptil, representada por um padrão de dobramento com eixos predominantemente NW e dobras em cúspide ou chevron, usualmente com vergência pouco definida ou com fraca vergência para leste. Entre os recursos minerais associados ao Grupo Bambuí destacam-se o calcário e o verdete, este último um litotipo exclusivo e característico da Formação Serra da Saudade.
\end{abstract}

\begin{abstract}
This paper synthesizes results obtained during the mapping of the Luz Sheet (SE-23-YDV), carried out by the CODEMIG - CPMTC/UFMG project. The mapped region is dominated by Neoproterozoic pelites and carbonates of Bambuí Group, deformed under influence of the Brasília Belt. The analysis of the sedimentological and stratigraphic data indicates a marine genesis to the rocks of the Bambuí Group, in environments ranging from shallow to deep marine shelf. The rocks show a ductile to brittle deformation, represented by a fold pattern with NW axis and chevron to cuspate folds, usually without vergence or weakly vergent to east. The mineral resources founded are mainly limestones and potassic rich sediments denominated "verdete", the last an exclusive litotipe of Serra da Saudade Formation.
\end{abstract}

\section{INTRODUÇÃO}

A Folha Luz localiza-se na porção centro-oeste do estado de Minas Gerais, sendo acessada, a partir de Belo Horizonte, pela BR 262 (Fig.1). Mapeada em escala 1:250.000 pelos projetos Três Marias (Menezes
Filho et al. 1978) e São Francisco (Silva \& Tuller 2001), a área insere-se na borda oeste da Bacia do São Francisco. Por meio de contrato entre o CPMTC/UFMG e a CODEMIG foi realizado o mapeamento geológico em escala 1:100.000 da Folha Luz (Kuchenbecker, no prelo), cujos dados são aqui expostos.

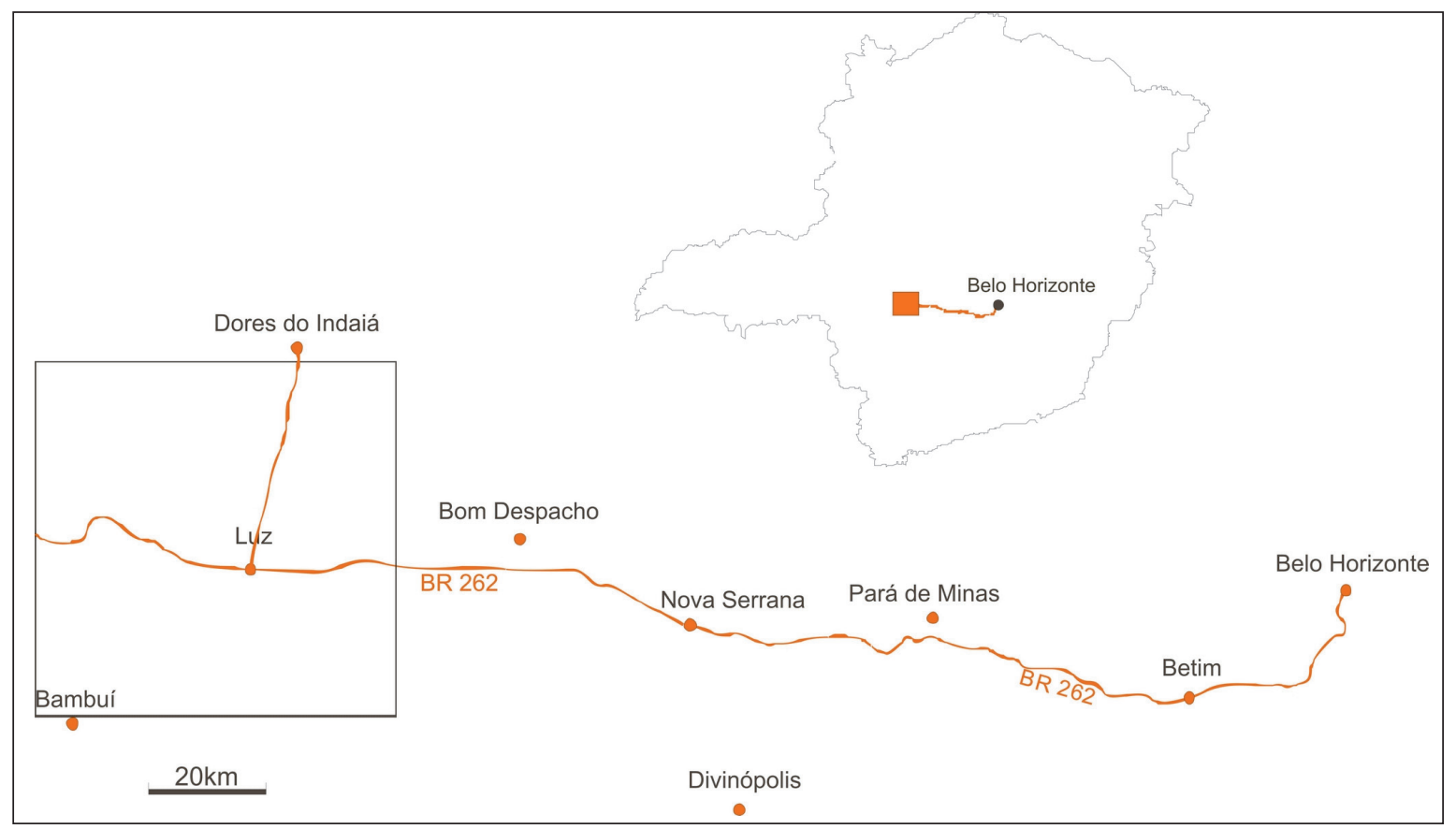

Figura 1. Localização da Folha Luz no estado de Minas Gerais e vias de acesso a partir de Belo Horizonte. Coordenadas limitrofes: $45^{\circ} 30^{\prime}-46^{\circ} \mathrm{W}, 19^{\circ} 30-20^{\circ} \mathrm{S}$.

1 - Universidade Federal de Minas Gerais, Instituto de Geociências, Departamento de Geologia, Programa de Pós-Graduação em Geologia Regional e Centro de Pesquisa Prof. Manoel Teixeira da Costa, Belo Horizonte (MG), Brasil.

E-mail: alemaogeo@gmail.com

2 - Centro de Pesquisas Professor Manoel Teixeira da Costa / Universidade Federal de Minas Gerais. Instituto de Geociências, Belo Horizonte (MG), Brasil.

E-mail: pedrosa@pq.cnpq.br 


\section{CONTEXTO GEOLÓGICO}

A área estudada insere-se nos domínios do Cráton do São Francisco, junto à sua borda oeste (Fig. 2). Predominam rochas sedimentares neoproterozóicas do Grupo Bambuí, ocorrendo subordinadamente rochas sedimentares e ígneas de idade cretácica, além de coberturas cenozóicas. do Jacaré, Serra da Saudade, reunidas no Subgrupo Paraopeba em RADAMBRASIL (1982), constituem depósitos carbonáticos e pelíticos de origem marinha, que são sobrepostos pelos depósitos areno-arcosianos plataformais da Formação Três Marias.

Na porção oeste da Bacia do São Francisco, as rochas do Grupo Bambuí foram afetadas por deformação do tipo thin skinned associada à edificação

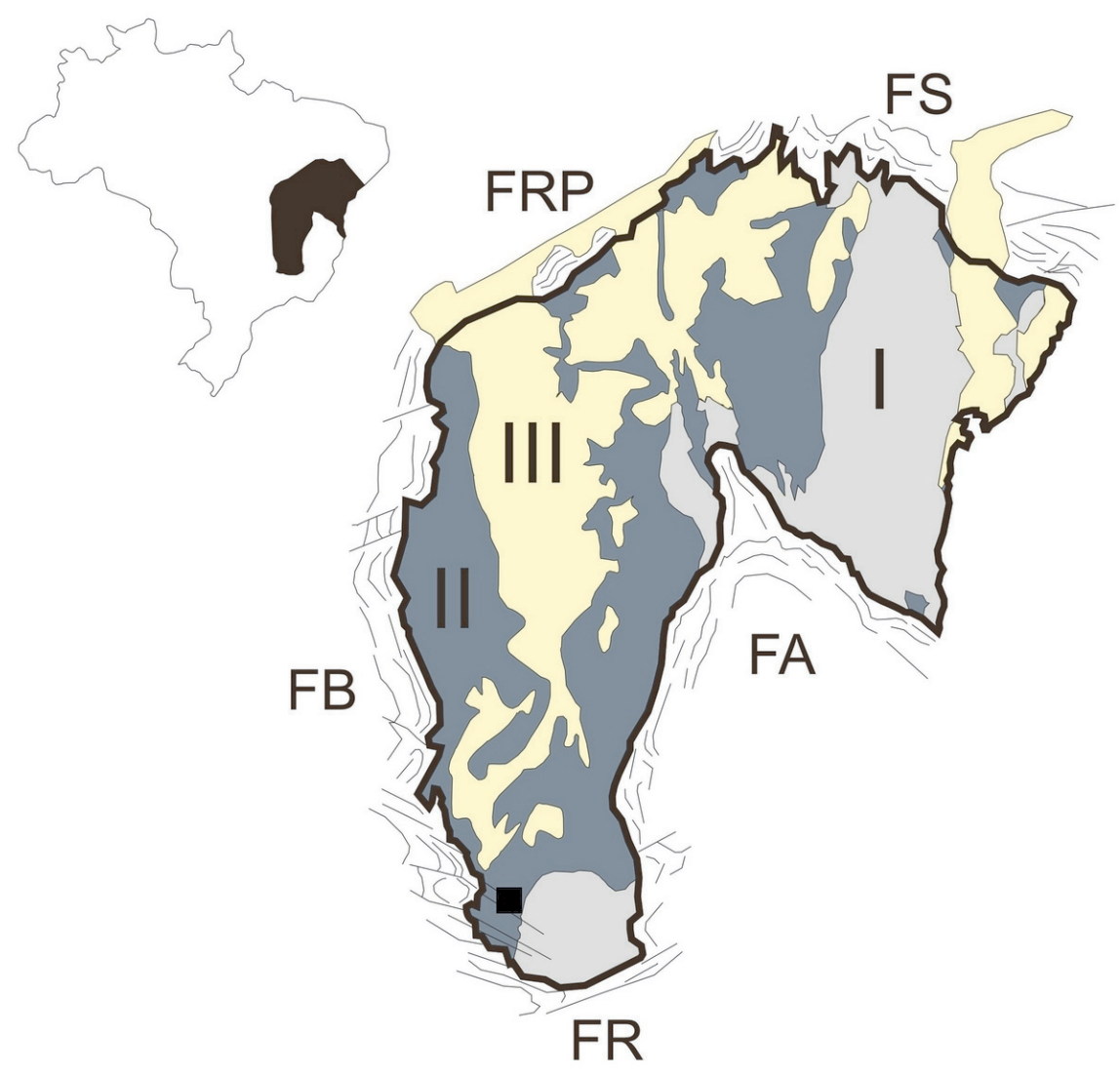

Figura 2. Situação da Folha Luz (quadrado preto) em relação ao Cráton do São Francisco. (I) Embasamento (> 1.8 Ga); (II) Bacia do São Francisco; (III) Cobertura Fanerozóica; FA - Faixa Araçuaí; FR - Faixa Ribeira; FB - Faixa Brasília; FRP - Faixas Rio Preto e Riacho do Pontal; FS - Faixa Sergipana. Modificado de Alkmim (2004).

Inserido no Supergrupo São Francisco (Pflug e Renger 1973), o Grupo Bambuí representa um espesso conjunto de rochas pelito-carbonáticas com eventuais depósitos grosseiros, que representam uma bacia do tipo foreland associada à edificação da Faixa Brasília durante o Neoproterozóico, na margem oeste do cráton do São Francisco (Martins-Neto \& Alkmim 2001, MartinsNeto 2009). A divisão litoestratigráfica vigente baseiase, com poucas modificações, nos trabalhos pioneiros de Costa \& Branco (1961) e Dardenne (1978), que consideram, da base para o topo, as formações Jequitaí, Sete Lagoas, Serra de Santa Helena, Lagoa do Jacaré, Serra da Saudade e Três Marias. A Formação Jequitaí é composta por sedimentos diamictíticos depositados sob influência glacial (Moraes \& Guimarães 1930, Couto \& Bez 1981, Karfunkel \& Hoppe 1988). As Formações Sete Lagoas, Serra de Santa Helena, Lagoa da Faixa Brasília, a oeste, acomodando-a na forma de um amplo sistema de dobramentos e zonas de cisalhamento localizadas. Maiores considerações sobre a estruturação das rochas da região podem ser encontradas em Muzzi-Magalhães (1989).

\section{O GRUPO BAMBUÍ NA FOLHA LUZ}

Diferentemente de áreas mais a sul, onde ocorrem amplos depósitos carbonáticos, a região de Luz é marcada pela predominância de rochas pelíticas, ficando os carbonatos restritos a lentes de dimensões variadas. Em consonância com os critérios adotados pela CPRM no Projeto Sete Lagoas-Abaeté (CPRM 2006), foram individualizadas as formações Serra de Santa Helena, Lagoa do Jacaré, Serra da Saudade, esta última subdividida em porção inferior e superior. 




Figura 3. Mapa geológico simplificado da Folha Luz, exibindo a distribuição das unidades do Grupo Bambuí.

\section{FORMAÇ̃̃O SERRA DE SANTA HELENA}

Restrita ao extremo SE da folha, a Formação Serra de Santa Helena foi delimitada na área com base nos contatos da Folha Bom Despacho (Ribeiro et al. 2008), a oeste. A unidade apresenta raríssimos afloramentos, uma vez que a maior parte da sua área de abrangência encontra-se coberta por depósitos coluvionares cenozóicos, onde são cultivados extensos canaviais.

O litotipo principal é um pelito, que ocorre invariavelmente alterado, em colorações que variam do bege ao laranja claro. Quando observável, o acamamento é marcado por laminação a estratificação plano-paralela, em geral sub horizontal.

\section{FORMAÇÃO LAGOA DO JACARÉ}

Representada por lentes carbonáticas que se concentram principalmente na porção sudeste da área mapeada, com ocorrências isoladas nas porções leste, noroeste e sudoeste. Apresentam dimensões métricas a quilométricas, e ocorrem completamente imersas nos pelitos descritos anteriormente, tendo suas principais exposições em pedreiras e morros na região de Lagoa da Prata. Em geral, os afloramentos de calcário exibem feição geomorfológica marcante, ocorrendo na forma de morrotes densamente vegetados, que se destacam das áreas baixas dominadas por pelitos.

Os litotipos mais freqüentes são calcarenitos e calcissititos, que exibem estratificação plano-paralela, estratificação ondulada e estratificações cruzadas tabulares em sets decimétricos. Ocorrem porções oolíticas a pisolíticas, caracterizadas por oólitos concêntricos, por vezes coalescentes, imersos em matriz esparítica (Fig. 4). Fácies intraclásticas são raras, e quando encontradas exibem intraclastos alongados, milimétricos a decimétricos, orientados segundo o acamamento. Freqüentemente são encontrados calcarenitos com construções estromatolíticas estromáticas e colunares. Podem ocorrer ainda camadas decimétricas a métricas de calcário ortoquímico.

Muito frequentemente os calcários apresentam pirita disseminada em baixas concentrações. Estruturas de dissolução ocorrem, sendo representadas principalmente por estilólitos e dissolution seams, normalmente paralelos à direção de acamamento.

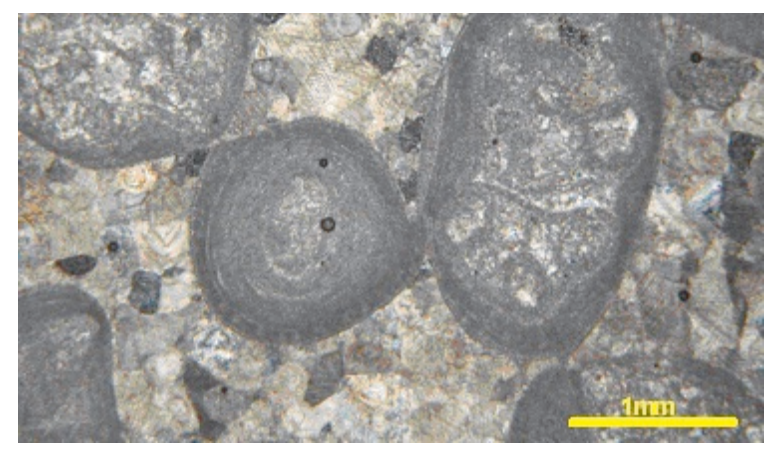

Figura 4. Fotomicrografia de calcário pisolítico, exibindo oólitos a pisólitos com estruturação concêntrica e localmente coalescentes, imersos em matriz esparítica. Luz analisada. 


\section{FORMAÇÃO SERRA DA SAUDADE (INFERIOR)}

Predominante na área, a unidade é caracterizada por um extenso pacote pelítico com raras intercalações arenosas. Afloramentos são encontrados com maior freqüência em cortes de estrada e encostas de morros. Nos fundos das drenagens de maior porte ocorrem os principais afloramentos de siltito fresco.

O litotipo predominante é um pelito, com silte e argila variando em diferentes proporções. Freqüentemente, com predominância de uma ou outra granulometria, ocorrem verdadeiros siltitos e argilitos, que podem ocorrer em pacotes mais espessos ou alternar-se em camadas centimétricas, dando à rocha um aspecto rítmico. Localmente ocorrem lentes e camadas descontínuas milimétricas a centimétricas de areia fina/muito fina, bem como camadas decimétricas de coloração escura, possivelmente ricas em matéria orgânica.

Em geral os afloramentos encontram-se intensamente intemperizados, exibindo colorações que variam de bege a vermelho. Observou-se que cores mais intensas ocorrem nas rochas com maior contribuição argilosa, enquanto as rochas com mais silte apresentam tons esmaecidos. Nos raros afloramentos frescos ou pouco intemperizados a rocha apresenta cor verde-clara a cinza.

Entre as estruturas sedimentares, destaca-se a laminação e estratificação plano-paralela, identificada principalmente através de variação granulométrica/ de cor e pela eventual presença das lentes arenosas. É notória a ocorrência de fragmentos detríticos de mica, que aparecem em concentrações variáveis marcando os planos de acamamento. Por vezes ocorrem laminações cruzadas e marcas onduladas (ripples) assimétricas, principalmente nas porções mais siltosas (Fig. 5).

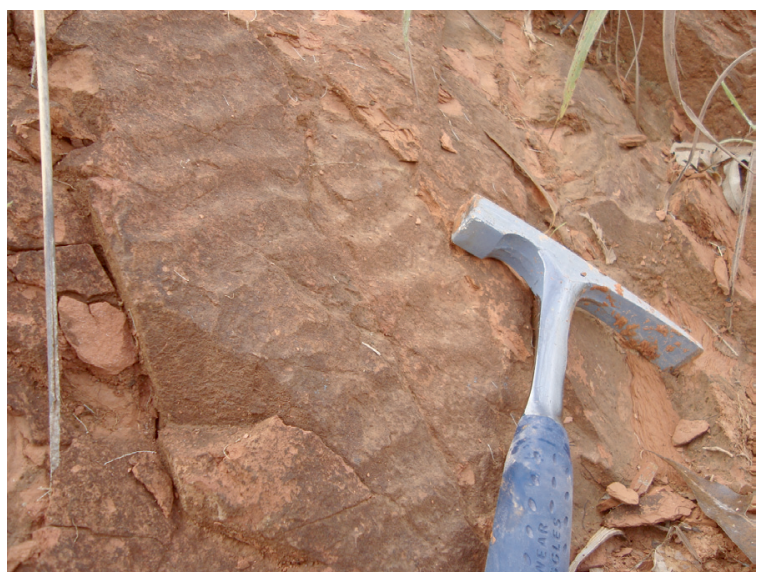

Figura 5. Marcas onduladas (ripples) assimétricas em siltito da Formação Serra da Saudade Inferior

Em lâmina delgada os siltitos são caracterizados por grãos angulosos a sub-angulosos de quartzo, raros grãos de feldspato e fragmentos detríticos de muscovita, envolvidos por matriz argilosa em proporções variáveis. A matriz apresenta-se em grande parte oxidada, indicando a presença de argilominerais ricos em ferro, e recristalizada, resultando no aparecimento de finos cristais de sericita e clorita. Minerais opacos ocorrem dispersos por toda a rocha em finos cristais. A natureza detrítica da muscovita pôde ser comprovada pela freqüente ocorrência de cristais deformados pelo processo de compactação por carga.

\section{FORMAÇÃO SERRA DA SAUDADE (SUPERIOR)}

Aflorante no quadrante NW da folha, na porção W da serra homônima, a Formação Serra da Saudade é caracterizada por uma diminuição da fração argilosa, com sutil aumento da fração areia fina nos sedimentos. Além disso, a unidade engloba todas as ocorrências de siltito e argilito de coloração verde intensa, conhecidos como verdetes.

O litotipo predominante é um siltito com pouca argila e proporções variáveis de areia fina, não raramente chegando a arenito fino. Afloramentos são relativamente abundantes, ocorrendo principalmente em encostas de morros e cortes de estrada. Quando encontrada fresca, o que se dá principalmente nos leitos de drenagens profundas, a rocha apresenta coloração verde clara a acinzentada. A maior parte dos afloramentos, no entanto, apresenta alto grau de intemperismo, conferindo às rochas cores que variam do bege ao rosa, sempre em tons mais "apagados". Por vezes ocorrem camadas decimétricas a métricas de arenito fino arcosiano a arcóseo, que podem apresentar coloração rósea escura a verde clara. Apesar de serem encontradas camadas maciças, na maior parte das vezes as rochas apresentam estratificação/laminação plano paralela e localmente laminação cruzada e truncamentos de porte centimétrico. Em lâmina delgada verificam-se grãos de quartzo tamanho silte a areia fina, usualmente angulosos a sub-angulosos. Feldspatos ocorrem em variadas proporções (até 20\%), configurando desde siltitos/arenitos finos arcoseanos a verdadeiros arcóseos. Grãos de mica detrítica, por vezes deformados por compactação, e pequenas quantidades de matriz argilosa também ocorrem com freqüência.

Os verdetes afloram preferencialmente nos altos dos morros, sendo o litotipo predominante em diversos locais. Muito raramente são encontrados, também em porções altas, como camadas e lentes, centimétricas a métricas, intercaladas nos siltitos, arenitos e arcóseos descritos anteriormente. Os principais afloramentos ocorrem às margens da BR 262, na travessia da Serra da Saudade.

$\mathrm{Na}$ maioria dos casos constituem um siltito, localmente com contribuição argilosa significativa, com coloração típica verde intensa (Fig. 6). Nos perfis mais intemperizados a rocha apresenta forte descoloração, passando a exibir tons de verde mais claros, esbranquiçados a arroxeados. Em lâmina delgada, os termos mais argilosos apresentam-se como uma massa homogênea, esverdeada, composta 


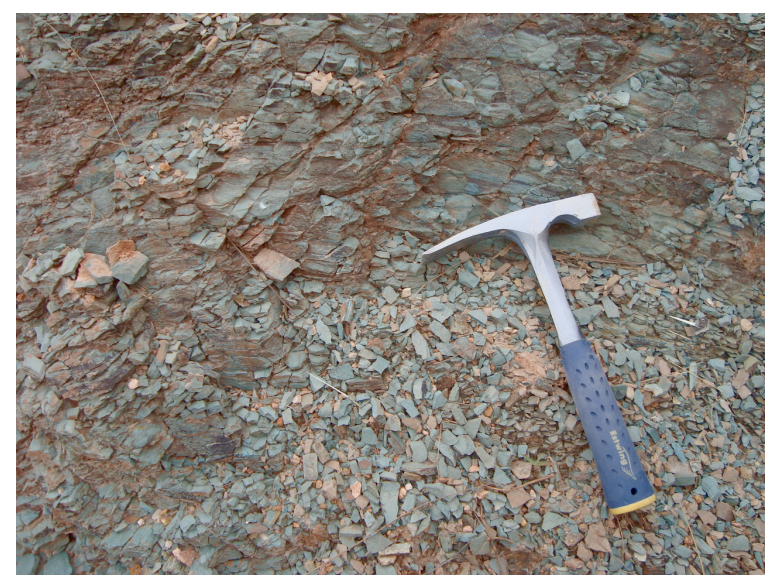

Figura 6. Afloramento de verdete, exibindo típica coloração verde intensa.

por argilominerais, provavelmente com glauconita, suportando cristais de sericita de aspecto neoformado.

\section{GEOLOGIA ESTRUTURAL}

A área mapeada apresenta como padrão estrutural mais marcante um amplo sistema de dobramentos, caracterizado por dobras de eixos preferencialmente NW que sofrem inflexão para NNW no norte da área (Fig. 7). Em geral são dobras decimétricas a métricas, abertas a fechadas, com eixos em mergulhos suaves a moderados para $\mathrm{NW}$ ou $\mathrm{SE}$, mas não raramente horizontais. Apresentam geometria em chevron e muito frequentemente uma geometria peculiar, com anticlinais angulosos ou em cúspide e sinclinais lobados.

Frequentemente observa-se dobras simétricas e com superfície axial subvertical, sem vergência definida (Fig. 8). Em diversos locais, porém, as dobras apresentam clara vergência para os quadrantes leste, o que também ocorre com as demais estruturas assimétricas.

Estruturas lineares são raras e, quando encontradas, representam em sua maioria estrias de deslizamento interestratal formadas durante o dobramento.

Falhas e zonas de cisalhamento compressivas são

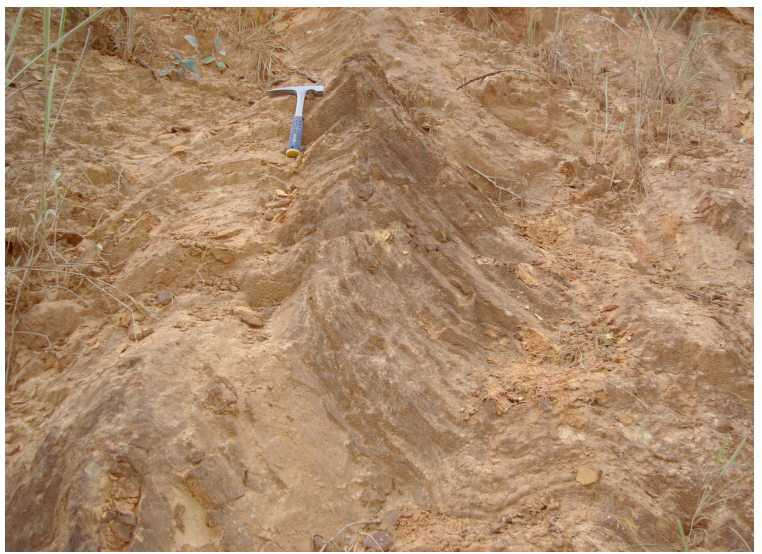

Figura 8. Dobra sem vergência definida em siltito do Subgrupo Paraopeba Indiviso. Notar geometria em cúspide.

encontradas principalmente na porção oeste da folha, ocorrendo desde truncamentos decimétricos a zonas decamétricas com estruturas sigmoidais e padrões complexos de deformação interna, via de regra, apresentando vergência para os quadrantes SE ou NE. Uma grande zona de cisalhamento compressiva de direção NS e vergência para E foi interpretada na porção oeste da folha, a partir de lineamentos de relevo e de estruturas de cisalhamento (e.g. grandes truncamentos e estruturas sigmoidais) encontradas ao longo de seu traçado (vide Fig. 3).

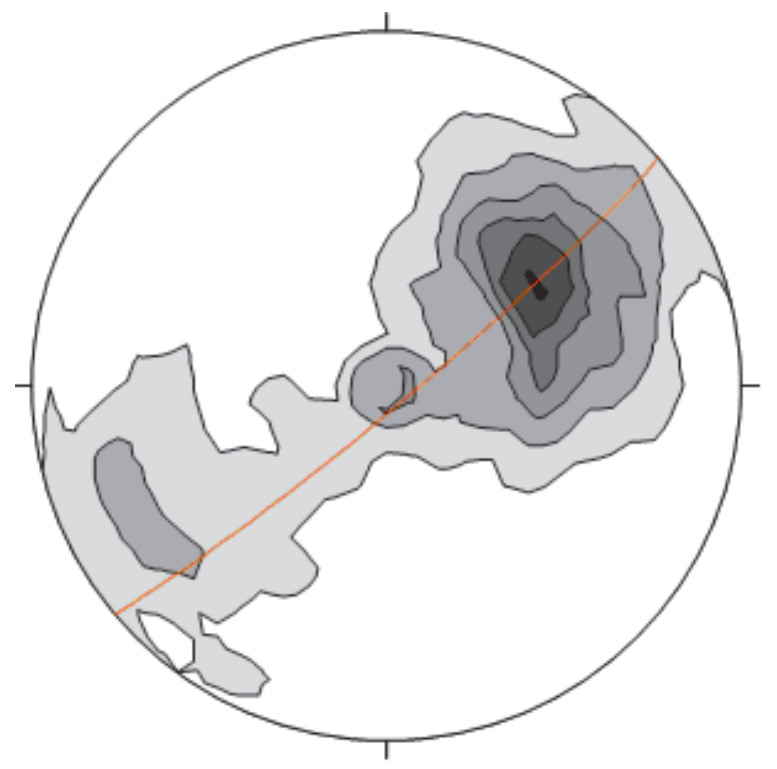

S0

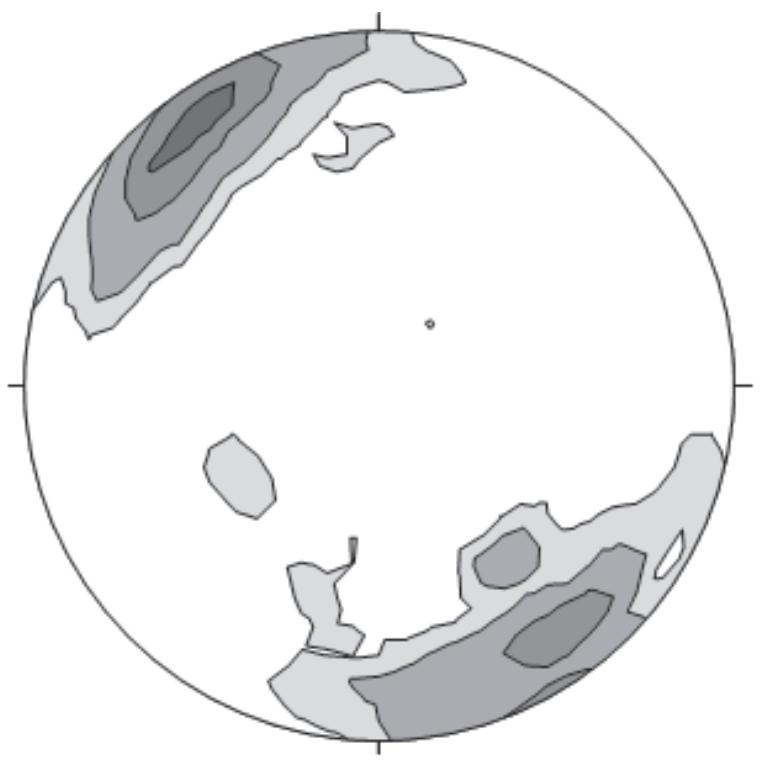

B

Figura 7. (A) Diagrama de densidade de pontos polares das medidas de acamamento. $n=660 ;$ Máximo= 60/48; $\pi a c=140 / 85$, em vermelho; (B) Diagrama de densidade das medidas de eixo de dobra. $n=282$;

Máximo=328/12. 
Os pelitos afetados pelas zonas de cisalhamento, quando intemperizados, tornam-se extremamente quebradiços, e seu desmantelamento dá origem a uma infinidade de pequenos fragmentos tabulares. Outra característica destas zonas é a ocorrência de cristais disseminados de pirita (limonitizada), em geral euédricos, podendo alcançar dimensões centimétricas.

Também na porção oeste da área ocorre, muito raramente, uma foliação $\mathrm{Sn}$ aparentemente relacionada às zonas de cisalhamento, caracterizada por planos pouco contínuos e pouco penetrativos, aos quais associam-se localmente estruturas do tipo SC. Na maioria dos casos apresentam mergulhos altos a moderados para SW ou NW.

A existência de zonas de cisalhamento na direção NW e de rejeitos aparentes nas imagens aerogeofísicas, possibilitou a inferência de uma expressiva zona de cisalhamento transcorrente sinistral na porção oeste da área, paralela à grandes lineamentos magnéticos.

Fraturas ocorrem de maneira onipresente na área como duas ou três famílias principais, a N50E, N80E e N70W. Em geral apresentam mergulhos altos e, em menor proporção, moderados.

\section{METAMORFISMO}

Apesar da deformação observada na área, feições metamórficas são muito escassas e dúbias, senão inexistentes. Macroscopicamente não se observa o crescimento de minerais metamórficos, uma vez que os litotipos mais comuns apresentam granulometria muito fina e os cristais de mica, quando observados, parecem ter origem detrítica.

Em lâmina delgada, no entanto, às vezes são observados finos cristais de sericita e clorita, neoformados a partir da matriz argilosa de siltitos/ arenitos fino, o que pode indicar condições de pressão e temperatura anquimetamórficas a fácies xisto verde baixo para as rochas da área mapeada.

\section{RECURSOS MINERAIS}

O principal recurso mineral relacionado ao Grupo Bambuí na área é o calcário, que ocorre principalmente na porção sul da folha. Algumas minas encontramse em atividade, em sua maioria explotando a rocha como insumo para a construção civil (brita e blocos) e subordinadamente produzindo pó calcário para correção de solo.

Merece destaque também a ocorrência de verdete, litotipo típico e exclusivo da Formação Serra da Saudade Superior, que aflora em áreas extensas na porção NW da área. Por apresentar grande quantidade de glauconita, o verdete vem sendo estudado como fonte alternativa de potássio (Piza et al. 2009), inclusive para utilização em técnicas de rochagem. Sua íntima associação com os depósitos de fosfato de Cedro do Abaeté (Lima et al. 2007, Boujo et al. 1994) o colocam também como um interessante proxie para a prospecção deste bem mineral.

Adicionalmente, a região apresenta algum potencial para a pesquisa de hidrocarbonetos, dada a ocorrência de raras camadas decimétricas ricas em matéria orgânica em meio aos pelitos da Formação Serra da Saudade Inferior.

\section{DISCUSSÃO}

A despeito da deformação onipresente na área, foram observadas características que indicam para as rochas do Grupo Bambuí uma gênese marinha. Ainda que a escala de realização do trabalho impossibilite assertivas seguras a respeito da gênese dos sedimentos, são aqui colocadas algumas considerações no sentido de contribuir para o estudo de tais rochas.

Os carbonatos da Formação Lagoa do Jacaré correspondem em grande parte ao "Calcário de Topo" de Madalosso \& Veronese (1978), apresentando em sua maioria, fácies de águas rasas e agitadas, a exemplo dos calcarenitos e calcarenitos oolíticos descritos. Assim, seu desenvolvimento deve ter ocorrido em plataforma rasa proximal, sob ação de ondas normais, com corpos recifais estromatolíticos dispersos. Localmente haveria a atuação de correntes, possivelmente associadas a fluxo de maré entre as bioconstruções, dando origem a estratificações cruzadas tabulares nos calcarenitos. A plataforma teria sofrido raros períodos de exposição, causando ressecamento e quebra de fragmentos, posteriormente retrabalhados nos níveis intraclásticos. $\mathrm{O}$ fato de os carbonatos ocorrerem em lentes em meio às demais rochas pode ser reflexo de controle da sedimentação pela paleogeografia da bacia ou pela influência da disposição irregular de grandes corpos recifais.

As características dos depósitos pelíticos que compõem as formações Serra de Santa Helena e Serra da Saudade Inferior sugerem deposição em ambiente marinho distal, em águas calmas onde predominaria a decantação de partículas finas. Episodicamente chegariam a esta porção da bacia correntes oriundas das zonas mais rasas, trazendo sedimentos arenosos em quantidades variáveis e gerando ripples assimétricas e laminações cruzadas observadas.

Para os depósitos da Formação Serra da Saudade são sugeridas condições de deposição marinha algo mais proximal, o que explicaria o sutil aumento granulométrico observado. Quanto aos verdetes, se a glauconita responsável pela coloração verde intensa possuir origem sin-sedimentar, sua presença indicaria deposição em porções externas da plataforma, em zonas de baixo aporte sedimentar, afastada da foz dos rios (Lima et al. 2007). No entanto, devido à distribuição errática destes depósitos e ao seu controle topográfico, uma gênese secundária, supergênica, não é descartada, hipótese mais coerente com as características sedimentares observadas. 


\section{AGRADECIMENTOS}

Os autores manifestam agradecimentos à CODEMIG e à toda equipe de mapeamento do CPMTC/UFMG, essenciais para a realização deste trabalho.

\section{REFERÊNCIAS}

ALKMIM F.F. 2004. O que faz de um cráton um cráton? O cráton do São Francisco e as revelações almeidianas ao delimitá-lo. In: Mantesso-Neto, V. et al. (ed.) Geologia do Continente SulAmericano: Evolução da Obra de Fernando Flávio Marques de Almeida, p. 17-34, São Paulo, Beca, 647p.

BOUJO A., TROMPETTE R., FLICOTEAUX R., MELFI A. J., AFFATON P., BLOT A., MONTEIRO M. D., DE OLIVEIRA J. J., MAGAT P. 1994. Fosfatos Sedimentares Marinhos do Proterozóico Médio e Superior e do Cambriano da África e do Brasil: Geologia, Mineralogia, Geoquímica e Importância Econômica. Anais da Academia Brasileira de Ciências, 66 (3), 293-318.

COSTA M.T. \& BRANCO J.J.R. 1961 .Introdução. In: Branco, J.J.R. (Ed.). Roteiro para a excursão Belo Horizonte - Brasília. In: SBG Congresso Brasileiro de Geologia, Belo Horizonte, v. 15, p.1-119.

COUTO J.G.P. \& BEZ L. 1981. A Glaciação Jequitaí. Um guia estratigráfico para o Precambriano Superior. Revista Brasileira de Geociências, 11, 17-21.

CPRM - Serviço Geológico do Brasil. 2006. Projeto Sete LagoasAbaeté. Disponível em: http://www.cprm.gov.br/publique/ cgi $/$ cgilua.exe/sys/ start.htm?infoid=361\&sid=26. Acesso em: $15 / 12 / 2010$.

DARDENNE M.A. 1978. Síntese sobre a estratigrafia do Grupo Bambuí no Brasil central. In: SBG, Congresso Brasileiro de Geologia, 30., Recife. Anais, v.2, p. 597-610.

KARFUNKEL J. \& HOPPE A. 1988. Late proterozoic glaciation in central-eastern Brazil: synthesis and model. Palaegeography, Palaeoclimatoogy and Palaeoecology, 65, 1-21.

KUCHENBECKER M. (no prelo). Mapa geológico da Folha Luz. Belo Horizonte, Companhia de Desenvolvimento Econômico de Minas (CODEMIG), mapa geológico, escala 1:100.000.
LIMA O. N. B., UHLEIN A., BRITTO, W. 2007. Estratigrafia do Grupo Bambuí na Serra da Saudade e geologia do depósito fosfático de cedro do Abaeté, Minas Gerais. Revista Brasileira de Geociências, 37(4), 204-215.

MADALOSSO A., VERONESE V. F. 1978. Considerações sobre a estratigrafia das rochas carbonatadas do Grupo Bambuí na região de Arcos, Pains e Lagoa da Prata (MG). In: Congresso Brasileiro de Geologia, 30. Anais. Recife, SBG. 2, p. 635-648

MARTINS-NETO M. A. 2009. Sequence stratigraphic framework of Proterozoic successions in eastern Brazil. Marine and Petroleum Geology, 26, pp. 163-176

MARTINS-NETO M. A., ALKMIM F. F. 2001. Estratigrafia e Evolucão Tectônica das Bacias Neoproterozóicas do Paleocontinente São Francisco e suas Margens: Registro da Quebra de Rodínia e Colagem de Gondwana. In: Pinto C. P., Martins- Neto M. A., (Eds.), Bacia do São Francisco: Geologia e Recursos Naturais. Belo Horizonte (SBG/ MG), p.31-54.

MENEZES FILHO N. R., MATOS G. M. M., FERRARI P. G. 1978. Projeto Três Marias. Belo Horizonte. Convênio DNPM/ CPRM, 339 p.

MORAES DE L. J. \& GUIMARÃES D. 1930. Geologia da região diamantífera do norte de Minas Gerais. Anais da Academia Brasileira de Ciências, 2, 153-186.

PFLUG R. \& RENGER F. E. 1973. Estratigrafia e evolução geológica da margem SE do Cráton Sanfranciscano. In: SBG, Congresso Brasileiro de Geologia, 27. Aracaju, Anais, 2, p. 5-19.

PIZA P. A. T., FRANÇA S. C. A., BERTOLINO L. C. 2009. Verdete do Cedro de Abaeté (MG) como fonte alternativa para potássio. Anais da XVII Jornada de Iniciação Científica do CETEM. p.192-198.

RADAMBRASIL. 1982. Folha SD.23, Brasília. Levantamento de Recursos Naturais. Rio de Janeiro, 29, 660p.

RIBEIRO J. H., TULLER M. P., SIGNORELLI N., FÉBOLI W. L. 2008. Mapa Geológico da Folha Bom Despacho (1:100.000). Belo Horizonte: CPRM.

SILVA P. C. S., TULLER M. P. 2001. Projeto São Francisco: folha Bom Despacho. Escala 1:250.000. Belo Horizonte: CPRM.

VIEIRA L. C., TRINDADE, R. I. F., NOGUEIRA, A. C. R. \& Ader M. 2007. Identification of a Sturtian cap carbonate in the Neoproterozoic Sete Lagoas carbonate platform, Bambuí Group, Brazil. C. R. Geosci., 339, 240-258. 